\title{
ESPORTE ADAPTADO COMO TEMA DA EDUCAÇÃO FÍSICA ESCOLAR
}

\author{
Marina Brasiliano Salerno
}

Paulo Ferreira de Araújo

\section{Resumo}

O esporte integra os temas tratados pela Educação física e por anos foi o dominante na escola regular com o objetivo de encontrar talentos em modalidades convencionais. Apos discussões na área, entende-se o esporte de forma ampla, com influencias em diferentes âmbitos da sociedade. Com a concepção de esporte enquanto fenômeno social deve-se oferecer diferentes vivencias dentro do tema, sendo uma delas os esportes para pessoas com deficiência, adaptadas ou criadas para essa população. Assim, sendo uma forma de expressão, o esporte para as pessoas com deficiência deve fazer parte do currículo da Educação física escolar. As possibilidades foram propostas em uma escola estadual do município de Campinas, com alunos de $4^{\mathrm{a}}$ serie do Ciclo I. As vivencias envolveram não apenas modalidades esportivas, como também pesquisas na internet e discussões sobre causas e conseqüências das deficiências.

\section{Palavras-Chave}

Esporte; Pessoas com deficiência; Educação Física escolar.

\section{ADAPTED SPORT AS SUBJECT OF THE SCHOOL PHYSICAL EDUCATION}

\section{Marina Brasiliano Salerno}

Paulo Ferreira de Araújo

\begin{abstract}
The sport combines the subjects covered by the physical education and for years was the dominant content at school with the goal of finding talent in conventional sports. After discussions in the area, the sport is understood widely, with influences in different areas of society. With the development of sport as social phenomenon should be offering different experiences in the subject, one of which the sports for people with disabilities, adapted or created for this population. So, being a form of expression, the sport for the disabled people must be part of the curriculum of physical education at school. The possibilities were proposed in a state school of the municipality of Campinas, with students from $4{ }^{\text {th }}$ grade of Cycle I. The experiences involved not just sports, but also searches on the Internet and discussions on causes and consequences of deficiencies.
\end{abstract}

\section{Key-Word}

Sports; People with disabilities; Physical Education at school. 


\section{INTRODUÇÃO}

Traçar a historia da Educação física e perceber a preocupação de ampliar as possibilidades de realização de atividades físicas para toda a população interessada.

Atualmente encontram-se atividades para gestantes, bebes - trabalhos que se propõem a estimular recém nascidos ate certa idade, crianças em creches, crianças e adolescentes do ensino fundamental e médio, adultos, idosos, pessoas com deficiência, entre outros. Cada grupo pode, ainda, ser subdividido caso apresente particularidades ou de acordo com interesses dos grupos, ou seja, trabalhar com modalidades esportivas, ou danças, ou esportes na natureza, atividades inseridas no contexto da Educação física.

Alem dessas possibilidades, ha adequação das propostas de acordo com o local a ser trabalhado, ou seja, encontramos a ginástica laboral aplicada em empresas, trabalho em conjunto com reabilitação, entre outros.

Dessa forma, percebe-se que a evolução da área da Educação física se deve a tentativa de englobar os mais diferentes públicos, oportunizando desde a vivencia ate o treinamento das diferentes atividades que compõem os conhecimentos que a Educação física oferece.

No âmbito escolar, a preocupação de melhorar a disciplina Educação física faz com que ocorram constantes discussões sobre quais temas devam ser tratados nos anos escolares.

Historicamente, a Educação física escolar foi um momento excludente dentre as disciplinas desse espaço. Buscava, inicialmente, formar homens saudáveis para poder defender o pais em possíveis confutes, ou então, formar também o homem saudável para que ele pudesse trabalhar as longas horas exigidas nas recém chegadas fabricas (DARIDO, 2003).

Apos essa predominante busca pelo corpo perfeito, o esporte passou a dominar o discurso daqueles que determinavam os conteúdos a serem trabalhados nas escolas. $\mathrm{O}$ argumento vigente foi a necessidade de buscar talentos esportivos para representar o país em competições.

A partir dessa linha, a Educação física escolar passou a contar com aulas esportivizadas, porem, não com o intuito de aprender sobre as modalidades e o fenômeno esporte, e sim, aprender os gestos técnicos necessários para se tornarem atletas. 
Dessa forma, professores de Educação física que apresentassem maior afinidade com uma das modalidades, ofereciam aulas sobre aquelas modalidades apenas, não possibilitando a vivencia de demais modalidades.

Com isso, apresenta-se o quadro que envolve discussões sobre a presença do esporte na escola e não o esporte da escola, questões envolvendo a especialização precoce, a diferença no tempo de maturação, ou seja, um menino que se apresentasse como o maior da sala em uma das series seria considerado um futuro promissor no que dizia respeito ao basquete, porem, não necessariamente nos anos seguintes ele se manteria o maior da turma, entre outros temas pertinentes (PAES, 1996).

Através dessas reflexões a Educação física escolar inicia a busca sua identidade no que diz respeito as possíveis áreas de atuação e conteúdos pertinentes ao âmbito escolar. Diferentes abordagens surgem para suprir essa falta de característica dessa área de conhecimento.

Uma delas e a abordagem crítico-superadora que tem como obra principal a Metodologia do Ensino da Educação Física, escrito por um coletivo de autores, sendo eles: Carmem Lucia Soares, Lino Castellani, Valter Bracht. Essa obra propõe o trabalho com os diferentes temas que constituem a chamada cultura corporal: dança, jogo, ginástica, luta e esporte. Outros temas podem ainda ser englobados como atividades circenses e teatrais.

Percebemos que o esporte não perde seu espaço no âmbito escolar, porem, o esporte proposto para ser trabalhado na Educação física escolar não e baseado em gestos técnicos e sim na compreensão de um fenômeno e suas diferentes formas de aparição na sociedade. Isso envolve não apenas as modalidades esportivas convencionalmente ensinadas por anos: futebol, basquetebol, voleibol e handebol, e sim outras modalidades esportivas que atualmente são difundidas pelo pais, dentre elas: badminton, rope skipping, tenis de mesa, entre outros.

Compreendendo, assim, o esporte como um fenômeno socio-cultural, pensa-se na possibilidade de apresentar aos alunos das escolas regulares os esportes praticados pelas pessoas com deficiência.

A trajetória do esporte para as pessoas com deficiência tem inicio apos a II Guerra Mundial, momento no qual os paises recebem de volta seus heróis de guerra, muitos deles com lesões graves, tais como: amputações, lesões medulares, entre outros. 
Com esse numero de pessoas que adquiriram uma condição de deficiência durante a defesa de seu pais em uma guerra, os centros de reabilitação passam a, dentro de seu quadro de atividades, oferecerem atividades esportivas adaptadas as condições dos, ate então, pacientes.

Um dos centros de referenda na historia do esporte para as pessoas com deficiência e o Hospital de Stoke Mandeville, sob coordenação do Dr. Guttmann. Por iniciativa dos profissionais desse hospital, alem de apresentar aos pacientes o esporte, foram organizados campeonatos, inicialmente intemos. Apos essa fase, passam a ser organizados jogos entre centres de diferentes paises, ate alcançar a periodicidade das Olimpíadas.

A partir de então, paralelamente as Olimpíadas ocorriam os Jogos de Stoke Mandeville que apos algumas edições passaram a ser chamados de Paraolimpiadas. O termo "para" utilizado para o evento Paraolimpíadas vem dos participantes que, inicialmente, eram apenas paraplégicos, permanecendo o termo apos a inserção de pessoas com outros tipos de deficiência.

A partir desse movimento de possibilitar as pessoas com deficiência a pratica esportiva, houve a ampliação da compreensão da capacidade das pessoas com deficiência nos diferentes âmbitos da sociedade.

Diversos esportes passaram a ter suas regras adaptadas para possibilitar as pessoas com deficiência a sua pratica e treinamento. Assim, a utilização de termos diferenciados são explicitados por Araújo (1998).

O autor inicia definindo o termo atividade adaptada fazendo uso das palavras de Rodrigues 1996 apud Araújo, 1998, p. 18-19:

Este termo parece sugerir que a atividade e estandardizada e que, para ser praticada por pessoas com deficiência necessita ser adaptada. Esta lógica funciona, por exemplo, para referir ao basquete em cadeira de rodas, mas será que verdadeiramente a podemos usar com, por exemplo, a boccia, que foi criado exclusivamente para pessoas com paralisia cerebral? Talvez sim, dado que o termo adaptação tem também conotação que se identifica com a manipulação de variáveis ecológicas. A atividade, os materiais, os estilos de ensino, os enquadramentos, etc., tem que ser adaptados porque a pessoa tem menos possibilidade de adaptação. Adaptar uma atividade, em sentido lato, pode ser, pois, construir uma atividade para um objetivo definido - por exemplo, desenvolver a consciência corporal. Adaptação ou usando um termo mais genérico - a adaptabilidade pode se referir a modificações numa atividade padronizada. Referente a um desporto, pode criar um envolvimento especifico de atividade não padronizada e pode ainda criar um contexto com objetivos claramente terapêuticos ou reeducativos. 
Assim, percebe-se que a atividade adaptada pode acontecer diariamente e não apenas para as pessoas com deficiência e sim para todos os momentos e para todos os grupos que apresentarem necessidade de modificações das atividades ou de materiais para possibilitar sua execução.

Outro termo definido e o desporto adaptado, entendido como:

[...] experiências esportivas modificadas ou especialmente designadas para suprir as necessidades especiais de indivíduos. O âmbito do esporte adaptado inclui a integração de pessoas portadoras de deficiência com pessoas 'normals', e lugares nos quais se incluem apenas pessoas com condição de deficiência. (WINNICK, 1990 apud ARAUJO, 1998, p 18).

Nesse conceito incluem-se as modalidades que são baseadas em esporte existentes e conhecidos e que ocorrem adaptações de regras para que tais modalidades possam ser praticadas por pessoas com deficiência.

Encontram-se, também, esportes que foram criados exclusivamente para a população com deficiência (ARAUJO, 1998). Um exemplo de desporto para deficientes e o Goalball, atividade criada para e praticada exclusivamente por pessoas com deficiência visual.

Entende-se, assim, que o esporte para a pessoa com deficiência, seja ele adaptado de uma modalidade ja existente, ou então criado exclusivamente para a pratica de um determinado grupo, passa a integrar o tema esporte, entendido como um fenômeno que influencia a sociedade e por ela e influenciado.

Dessa forma, e esporte praticado pelas pessoas com deficiência, pode integrar os temas trabalhados no esporte no âmbito escolar, passando, assim, a interar o currículo da Educação física escolar.

Trabalhar esse tema no ensino regular não significa mostrar que pessoas debilitadas também poem praticar esporte comum sentido de "auto ajuda" e sim, para o conhecimento de uma expressão cultural das pessoas com deficiência. Através de estudos que abarquem não apenas os esportes, como também a deficiência em si, com suas causas e conseqüências, pode oportunizar aos alunos a compreensão que adaptações não significam impossibilidade ou menosprezo e sim a forma de garantir a participação de todos.

A vivencia de esportes adaptados também não fará com que alunos que não possuem algum tipo de deficiência passem a compreender as dificuldades enfrentadas no cotidiano de pessoas com deficiência, 
porém, percebera as diferenças de percepção auditiva, ou visual, de locomoção, entre outros, para a pratica desses esportes.

Essa interação com as diferenças pode fazer com que os alunos passem a respeitar as pessoas ao se redor, não apenas as pessoas em condição de deficiência, compreendendo que cada ser humano possui uma forma de perceber o mundo, nem melhor, nem pior, apenas diferente.

\section{MÉTODO}

Essas questões foram introduzidas em uma escola publica do município de Campinas durante dois bimestres de trabalho da disciplina de Educação física para as turmas de $4^{\text {as }}$ séries do Ciclo I.

As aulas foram acompanhadas pela professora que manteve seu diário de classe com anotações sobre as aulas ministradas, assim, podemos classificar a pesquisa como qualitativa com observação e anotação em diário (THOMAS; NELSON, 2002).

O trabalho teve início com pesquisas na internet utilizando o site de busca www.google.com.br. para localização de sites relacionados as deficiências. Foram escolhidos quatro diferentes condições de deficiência: auditiva, visual, física e mental.

Através dessa pesquisa, os alunos obtiveram dados referentes aos conceitos de cada deficiência bem como suas causas e conseqüências, fatos que fizeram os alunos refletirem sobre causas familiares e cuidados que deveriam ter ao longo da vida.

A partir desses conceitos, as turmas foram divididas em grupos para que os mesmos sistematizassem os conceitos encontrados sobre determinada condição de deficiência, suas causas, conseqüências e esportes que poderiam ser realizados pelos mesmos.

Tais dados foram apresentados em suas turmas correspondentes e discutidos para a formulação de um só texto com itens explicativos.

Apos formular os itens, foram confeccionados cartazes contendo os itens explicativos e figuras para melhor ilustra-los deixando-os auto-explicativos. 
Tais cartazes foram expostos na escola para apreciação dos diferentes períodos que compõem a escola e as $4^{\text {as }}$ series explicaram os conceitos para as $3^{\text {as }}$ series que dividem o mesmo período (manha).

Apos essa fase da compreensão de conceitos, causas e conseqüências, os alunos das $4^{\text {as }}$ series puderam vivenciar duas modalidades esportivas para pessoas com deficiência: o goalball e o vôlei sentado.

\section{DESCRIÇÃO DAS ATIVIDADES}

Previamente a realização das atividades propriamente ditas, foi proposta uma vivencia de caminhada com os olhos vendados. Em dupla, os alunos exploraram os diferentes espaços da escola sendo que um aluno fazia uso de vendas e o outro era o guia. Essa atividade proporcionou aos alunos a percepção da responsabilidade que existe em se guiar uma pessoa com deficiência visual e o que os alunos chamaram de coragem da pessoa com deficiência visual que deve, por vezes, confiar em desconhecidos. Os alunos levantaram essa questão relacionando a pouca confiança que eles possuem em estranhos na rua.

Apos essa fase, a professora propôs montar o espaço utilizado para se jogar o goalball. Os materiais utilizados foram: fita crepe, barbante e tesoura. Assim, os alunos com auxilio da professora montaram a quadra de goalball.

Alem da quadra, foram necessárias adaptações com relação ao gol, sendo que na modalidade sistematizada existem as traves do gol que ocupam o fundo da quadra todo e possuem altura de aproximadamente $1,30 \mathrm{~m}$ e a bola que e especifica para a modalidade contendo guizos em seu interior.

Os atletas de goalball fazem uso da trave para locomoção na largura do campo, assim, para uma primeira vivencia essas traves foram dispensadas da atividade, porem, uma adaptação possível seria a utilização de duas cadeiras com barbante amarrado.

A bola, porem, e item imprescindível para a realização do goalball, sendo necessário ouvir a sua trajetória para possibilitar a defesa. Dessa forma, como esse e um material que ainda não apresenta fácil acesso, utilizamos uma bola de borracha dentro de um saco plástico - dos encontrados em mercados. Assim, no momento no qual os alunos arremessavam a bola, ela fazia o barulho necessário para que houvesse a defesa da equipe adversária.

Todos os alunos tiveram a oportunidade de montar o campo a ser utilizado, bem como vivenciar a modalidade. 
A segunda modalidade apresentada foi o vôlei sentado. Para a realização dessa modalidade não são necessárias grandes adaptações, sendo necessário apenas diminuir a altura de uma rede de vôlei convencional e fazer os atletas jogarem sentados. Porem, na escola na qual foram realizadas essas atividades, não ha espaço adequado para a realização dos mesmos, ou seja, não ha espaço cimentado com possibilidade de armar uma rede de vôlei. Assim, os próprios alunos ficaram responsáveis por segurar a rede, sendo que os mesmos se revezavam nessa tarefa e na vivencia do vôlei sentado.

\section{DISCUSSÃO}

As atividades realizadas nas aulas de Educação física desde a pesquisa na internet sobre as deficiências ate a vivencia de modalidades para as pessoas com deficiência, os alunos perceberam que tratam as pessoas com deficiência como coitadas, porem, elas tem grandes possibilidades de realização.

Um fator citado por diversos alunos foi a questão de que as pessoas com deficiência não são tão diferentes de qualquer outra pessoa, ou seja, todos são diferentes.

Os alunos perceberam, ainda, que existem algumas mudanças não apenas nas modalidades esportivas, e sim, no comportamento daqueles que observam a modalidade. Durante a realização do goalball, por exemplo, os alunos que esperavam sua vez para jogar deveriam fazer silencio para que os jogadores pudessem ouvir a bola chegando ao seu campo.

Perceberam, também, que em alguns momentos, diferentes sentidos devem ser priorizados e que eles estavam muito acostumados a utilizar apenas a visão.

Questões como essas devem ser levadas em consideração, pois, em uma escola que não recebe alunos com deficiência, aqueles que freqüentam a escola não terão essa convivência, perpetuando um pensamento pequeno sobre as possibilidades da pessoa com deficiência. Dessa forma, as pesquisas e as vivencias realizadas por esses alunos fizeram com que houvesse a percepção da possibilidade, alem de apresentar outras modalidades esportivas que não apenas as convencionais.

Retomando os temas que podem ser tratados no âmbito escolar, devemos pensar nessas questões recentes que devem ser levadas a escola para ocorrer essas discussões, abrindo espaço para as mais diferentes formas de expressão do corpo. 
O esporte inserido no contexto escolar pode explorar as mais diversas formas de expressão, porem, não se pode, nesse momento, escolher poucas atividades para serem apresentadas. $\mathrm{O}$ esporte enquanto conteúdo da Educação física escolar deve oferecer aos alunos a vivencia de diferentes modalidades e discutir as diferentes repercussões do mesmo, dessa forma, apresentar o maior numero de atividades aos alunos faz com que os mesmos possam, futuramente, escolher uma atividade para praticar ou treinar.

A possibilidade do esporte para a pessoa com deficiência não ocorre apenas pelo movimento ou desenvolvimento de coordenação motora ou outros, ela pode fazer parte do contexto da Educação física escolar para acrescentar aos alunos a compreensão das diferenças e que o fenômeno esportivo pode ser para todos.

\section{REFERÊNCIAS}

ARAÚJO, P. F. Desporto adaptado no Brasil: origem, institucionalização e atualidade. Brasília: INDESP, 1998.

DARIDO, S. C. Educação física na escola: questões e reflexões. Rio de Janeiro: Guanabara Koogan, 2003.

THOMAS, J. R.; NELSON, J. K. Métodos de pesquisa em atividade física. 3. ed. Porto Alegre: Artmed, 2002. 419p.

PAES, R. R. Educação física escolar: o esporte como conteúdo pedagógico do ensino fundamental. 1996. 198 f Tese (Doutorado) - Faculdade de Educação , Universidade Estadual de Campinas, Campinas, 1996;

SOARES, C. L. et al. Metodologia do ensino de E

Educação Física. São Paulo: Cortez, 1992. 


\section{Marina Brasiliano Salerno}

Faculdade de Educação Física - UNICAMP

Paulo Ferreira de Araújo

Faculdade de Educação Física- UNICAMP

\section{Referência do artigo:}

\section{ABNT}

SALERNO, M. B., ARAÚJO, P. F. Esporte adaptado como tema da educação física escolar. Conexões, v. 6, p. 212-221, 2008.

\section{APA}

Salerno, M. B., \& Araújo, P. F. (2008). Esporte adaptado como tema da educação física escolar, 6, 212221.

\section{VANCOUVER}

Salerno, M. B., Araújo, P. F. Esporte adaptado como tema da educação física escolar. Conexões, 2008; 6 : 212-221. 